\title{
Digital Generating Method for Cylindrical Helical Gear based on Indexable Disk Milling Cutter
}

\section{Weiqing Zhang}

Chongqing University of Technology

Qing Zhou ( $\square$ zhouzhou@2019.cqut.edu.cn )

Chongqing Institute of Technology: Chongqing University of Technology https://orcid.org/0000-0001-

7654-5216

\section{Xiaodong Guo}

Chongqing University of Technology

\section{Rulong Tan}

Chongqing University of Technology

\section{Ruizhi Shu}

Chongqing University of Technology

\section{Research Article}

Keywords: Digital generation, Spatial free-form milling, Indexable disk, Milling efficiency

Posted Date: July 16th, 2021

DOI: https://doi.org/10.21203/rs.3.rs-708854/v1

License: (c) (i) This work is licensed under a Creative Commons Attribution 4.0 International License. Read Full License

Version of Record: A version of this preprint was published at The International Journal of Advanced Manufacturing Technology on January 23rd, 2022. See the published version at https://doi.org/10.1007/s00170-021-08533-x. 


\title{
Digital generating method for cylindrical helical gear based on indexable disk milling cutter
}

\author{
Weiqing Zhang, ${ }^{\mathrm{a}, \mathrm{b}, \mathrm{c}}$,Qing Zhou ${ }^{\mathrm{a}^{* 1}}$,Xiaodong Guo ${ }^{\mathrm{a}}$, Rulong Tan ${ }^{\mathrm{a}}$, Ruizhi Shu ${ }^{\mathrm{a}}$ \\ ${ }^{a}$ School of Mechanical Engineering, Chongqing University of Technology, 400054, China \\ ${ }^{\mathrm{b}}$ Chongqing Machine Tool (Group) Co., Ltd, 401339, China \\ c College of Mechanical and Vehicle Engineering, ChongqingUniversity,400030, China
}

\begin{abstract}
To solve the problem of low efficiency in digital generating machining for producing small or medium batches of helical gears, a method to improve the machining efficiency with an indexable disc milling cutter is presented in this paper. First, the mathematical model of the tooth profile and the indexable disc milling cutter are established. Second, according to the spatial free-form envelope theory, the overall planning scheme of the tool path is given; the relative position and the relative transformation matrix of the tool and tooth profile during digital generating machining using the indexable disc milling cutter are solved, the simulation cutting and actual cutting experiments are conducted, and the cutting efficiency per unit time and cutting simulation time of the two tools under the same deformation conditions is obtained through a finite element analysis experiment. The results show that the cutting efficiency of the indexable disc milling tool was 2-3 times higher than that of the end mill cutter.
\end{abstract}

Key words: Digital generation; Spatial free-form milling; Indexable disk; Milling efficiency

\section{Introduction}

Cylindrical gears are widely used for motion and power transmission between parallel shafts and are key basic parts in aviation, automotive, energy, and other fields. Traditional gear machining mainly adopts generating machining methods, such as gear hobbing and gear shaping [1 3]. However, with the gradual development of mechanical products in the direction of small-batch customization, the shortcomings of traditional gear processing methods (requiring special machine tools and special tools, long processing preparation cycles, and insufficient machine tool start-up rates) are increasingly prominent. This has led to the emergence of a digital generating method based on the spatial free-form envelope theory, which is realized by multiple-tool flank milling on a general-purpose multi-axis computer numerical control(CNC) machining center.

Regarding gear processing methods, scholars have conducted extensive research. Zhu [4] and Bo [5] presented a representation of the envelope surface of the tool sweep body for flank milling envelope processing and found numerous applications in the geometric problems arising from 5-axis flank milling. Harik [6] introduced the principle of 5-axis flank milling in detail and provided some suggestions on its tool path optimization. Guo [7]conducted a cutting mechanism for cylindrical gear power skiving. Tsai [8] proposed a

\footnotetext{
Qing Zhou

Tel: +86180840505027

E-mail: zhouzhou@2019.cqut.edu.cn
} 
method of using the power-skiving method on the a 6-axis CNC turn-mill machining center owing to the expense of dedicated power-skiving machining tools. Tang [9] proposed a method of machining a spur facegear on a 4-axis CNC planer. Lo [10] discovered a method to improve the efficiency of milling surfaces with a flat-end cutter by minimizing the tool path length in a 5-axis machining center. Pechard [11] dealt with tool path optimization in the flank milling of the 5-axis machining center based on the geometric deviation and smoothness of the tool path. Shih [12] proposed a free-form flank modification based on a 5-axis CNC helical gear profile grinding machine. Gong [13] illustrated a new tool path generation method for free-form surface flank milling considering the constraints for a ball-end cutter in a 5-axis machining. Guo [14] studied the machining error of a cylindrical gear tooth profile with an end milling cutter and obtained the relationship between the tooth profile accuracy and machining tool type, gear parameters, and feeding strategy of the tool. Michalski [15] analyzed the three-dimensional surface topography of cylindrical gear hobbing and chiseling. Özel [16] demonstrated the machining errors of the spur gear tooth profile with an end milling cutter according to the radial cutting method in a 3-axis CNC milling machine. Svahn [17] studied the tooth surface error of an involute gear machined by a form grinding wheel or form milling wheel. Chiang [18] proposed a mathematical method for determining the distribution of the cutter body and inserts, which is used in the rough machining of screws with form milling cutters with multiple insert. Zheng [19] studied the dynamics of spiral bevel gear face-milling with a disc milling cutter. Habibi [20] derived a semi-analytical formula for the undeformed cutting area and predicted the cutting force in the face-hobbing of bevel gears with a disc milling cutter. Shih [21] proposed a machining method for small or medium batch bevel gears with a disk milling cutter on a 5-axis machine because of the high production cost caused by special machine tools and cutters for face-milling and gear-hobbing of bevel gears.

Researchers have extensively worked on digital generating tool path planning and machining accuracy control of gears using end milling cutters, while the research on digital generating machining using disc milling cutters is mostly focused on spiral bevel gear machining; meanwhile, there is a lack of relevant research on digital spreading of cylindrical gears with disc milling cutters. Considering that the diameter of the end milling cutter is limited by the width of the tooth groove when machining small or medium-sized gears, the strength and material removal rate will be significantly reduced. In this paper, we present a digital generating method for machining cylindrical gears with indexable disc milling cutters and discuss the trajectory planning, tool positioning and interference avoidance. Thereafter, the accuracy of the tool location is verified by machining simulation and the efficiency of the milling tooth with a disc milling cutter by finite element cutting simulation. Finally, compared to the digital generation of gears with the end milling cutter, this method can improve the material removal rate of the machining gear to a considerable extent while maintaining the quality of tooth surface machining.

2 Mathematical model of tooth profile and indexable disc milling cutter 


\section{1 Deduction of tooth profile equation}

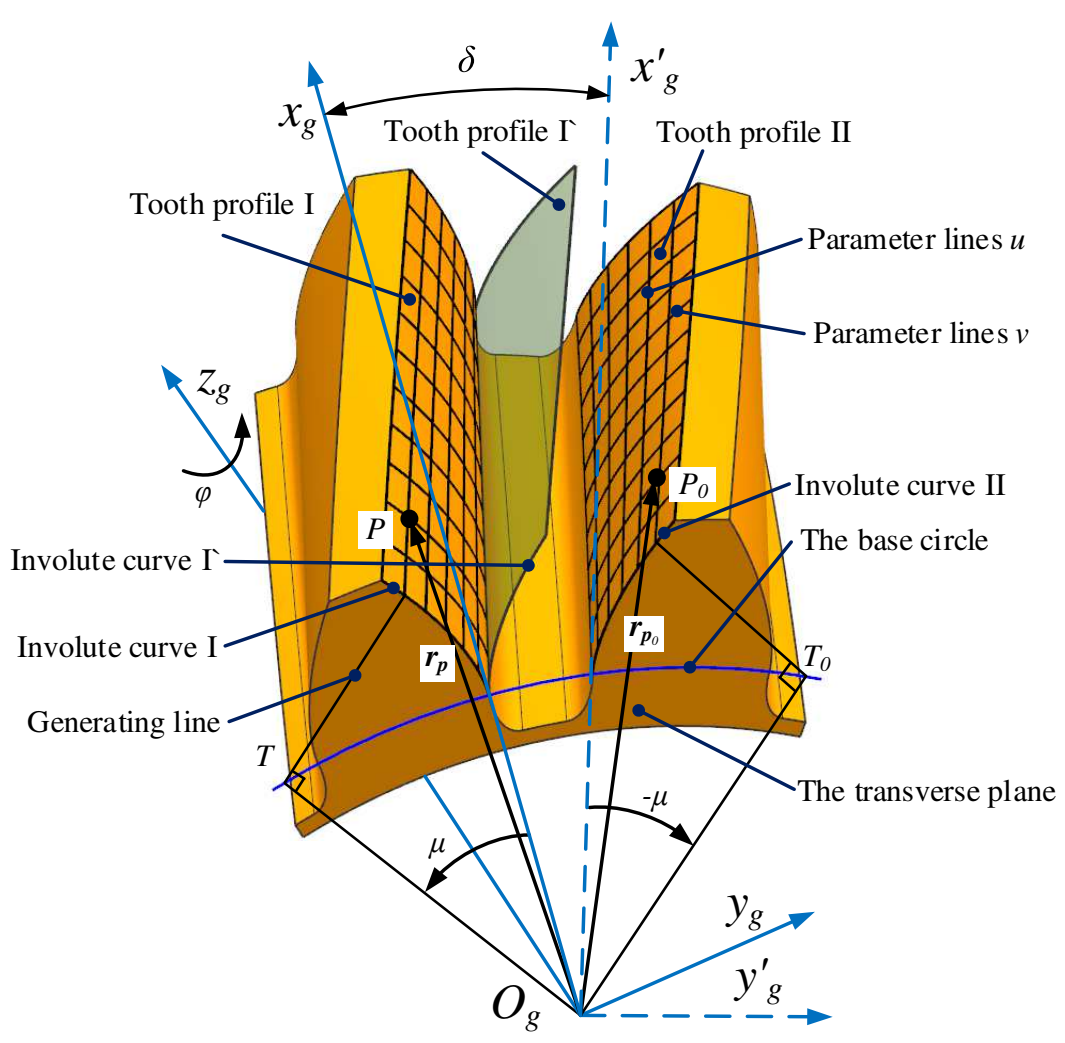

Fig. 1 Tooth surface formation of cylindrical helical gear

The tooth surface of a helical gear is a helicoid, as represented by Eq. (1). In derivation of this equation, it was assumed that the helicoid is generated by the screw motion of an involute curve in the cross profile (or the transverse plane) about the gear axis [22], as shown in Fig.1. Here $S_{g}=\left\{O_{g}, \boldsymbol{x}_{g}, \boldsymbol{y}_{g}, \boldsymbol{z}_{g}\right\}$ is the coordinate system rigidly connected with the gear, in which $O_{g}$ is the center of the base circle of the gear, $\boldsymbol{x}_{g} O_{g} \boldsymbol{y}_{g}$ coincides with the transverse plane of the gear, $+\boldsymbol{z}_{g}$ is the axis of the gear, $+\boldsymbol{x}_{g}$ and $\boldsymbol{+ x}_{g}$ are tangent to involute curves I and II at the base circle in the $\boldsymbol{x}_{g} O_{g} \boldsymbol{y}_{g}$, respectively. $+\boldsymbol{y}_{g}$ and $+\boldsymbol{y}_{g}$ are determined according to the right-hand rule. The tooth profile I and I' are respectively generated by the screw motion of involute curves I and I` around the gear axis by an angle $\varphi$. The involute curves I and I' are symmetrical about the $+\boldsymbol{x}_{g}$, and tooth profile II is obtained by rotating tooth profile I' around $+z_{g}$ by an angle $\delta$. The parameter lines $u$ and $v$ are generated by the screw motion of the involute in the transverse plane around the z-axis; therefore, the position vector of $P$ and $P_{0}$ in the coordinate system $S_{g}$ can be expressed by the parameters $\mu$ and $\varphi$ as follows:

$$
\boldsymbol{r}_{P}, \boldsymbol{r}_{P_{1}}=\left(\begin{array}{c}
r_{b} \cdot(\cos (\mu-\delta+\varphi)+\mu \cdot \sin (\mu-\delta+\varphi)) \\
r_{b} \cdot(\sin (\mu-\delta+\varphi)-\mu \cdot \cos (\mu-\delta+\varphi)) \\
r_{b} \cdot \varphi \cdot \cot \left(\beta_{b}\right)
\end{array}\right)
$$

At point $P, \delta$ takes 0 , and at point $P_{0}, \delta$ takes the calculated value and $u$ takes $-u$. Here $r_{b}$ is 
the radius of the base circle, the parameter $u$ is measured from the position vector in $O_{g} T$ in the direction shown in Fig. 1, $\varphi$ is the angle of rotation around $+z_{g}$, and $\delta$ is the angle between $+x_{g}$ and $+x_{g}$, which can be expressed as follows:

$$
\begin{gathered}
\delta=e / r-\delta_{e} \\
\delta_{e}=2 \cdot\left(\sqrt{r^{2}-r_{b}^{2}} / r_{b}^{2}-\arcsin \left(r_{b} / r\right)\right)
\end{gathered}
$$

Where $r$ is the reference circle radius and $e$ is the transverse space width.

\section{2 Establishment of mathematical model of indexable disc milling cutter}

Indexable disc milling cutters (hereafter referred to as disc milling cutters) mainly comprise a hilt and an insert with two sides (a side edge and the other side edge) that can be machined simultaneously; the two sides are connected by a tip fillet. The insert is fixedly connected to the handle by bolts, which not only avoids the shortcomings of integral cutters that are prone to cracks, but also realizes rapid replacement of blades of different materials according to the material of the blank, making its processing versatile and highly productive. Simultaneously, the large diameter and high strength of the disc milling cutter as well as the small fillet make it suitable for high-efficiency machining of gears with large feeds and the machining of narrow areas of tooth roots. Note that for the cross profile of the disc milling cutter shown in Fig. 2, $S_{t}=\left\{O_{t}, x_{t}, y_{t}, z_{t}\right\}$ is the coordinate system rigidly connected with the tool, $O_{t}$ is the cutter location of point, $x_{t} O_{t} y_{t}$ plane coincides with the bottom plane of the disc milling cutter, $+z_{t}$ is the cutter shaft, $+y_{t}$ coincides with the other edge, $+x_{t}$ is determined according to the right-hand rule, $r_{I D}$ is the nominal diameter of the disc milling cutter, $O_{c}$ is the center of the fillet, $r$ is the radius of the fillet, and $P_{1}, P_{2}$ and $P_{3}$ is an arbitrary cutting points on the side edge, the other edge, and the fillet, respectively. Hence, the position vectors of $P_{1}, P_{2}$, and $P_{3}$ in the coordinate system $S_{t}$ can be expressed as:

$$
\left.\begin{array}{c}
\boldsymbol{r}_{P_{1}}=\left(\begin{array}{c}
0 \\
l-l_{1} \cdot \cos \left(\alpha_{t}\right)+r \cdot \sin \left(\alpha_{t}\right) \\
r+l_{1} \cdot \sin \left(\alpha_{t}\right)
\end{array}\right) \cdot M(z, \psi) \\
\boldsymbol{r}_{P_{2}}=\left(\begin{array}{lll}
0 & l-l_{2} & 0
\end{array}\right) \cdot M(z, \psi)
\end{array}\right)
$$




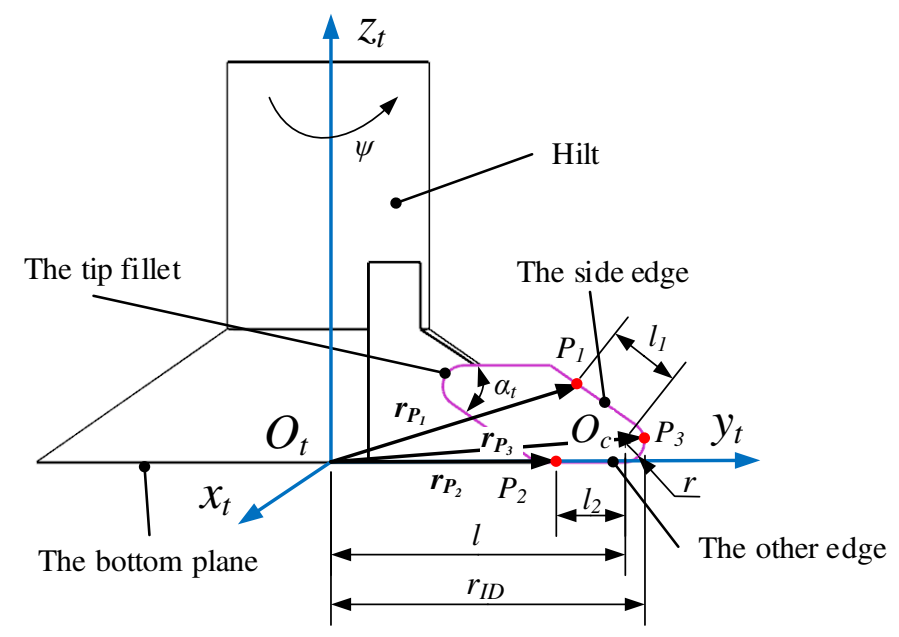

Fig. 2 Cross profile of the disc milling cutter

Here, $\alpha_{t}$ is the insert angle, $l$ is the projection distance from $O_{c}$ to $O_{t}$ at $+y_{t}, l_{1}$ is the projection distance from $P_{1}$ to $O_{c}$ at the side edge, $l_{2}$ is the projection distance from $P_{2}$ to $O_{c}$ at $+y_{t}, \theta_{r}$ is the angle between $r$ and $+y_{t}$, and $M(z, \psi)$ is the rotation matrix rotated by angle $\psi$ around $+z_{t}$, which can be expressed as follows:

$$
M(z, \psi)=\left(\begin{array}{ccc}
\cos (\psi) & \sin (\psi) & 0 \\
-\sin (\psi) & \cos (\psi) & 0 \\
0 & 0 & 1
\end{array}\right)
$$

\section{Cutting of the helical gear in 5 -axis machining center}

Disc milling cutters are often used for machining tooth grooves by adopting a variable contour milling strategy, as shown in Fig. 3. When machining the tooth groove, the first layer of cutting thickness and cutting tool path are determined by the cutting process and initial tooth surface parameters; after the first layer of machining, the tool feeds along the radial direction of the blank to start the second layer of cutting, and this cycles until the tooth groove processing is completed. In the cutting process of each layer (considering the first layer as an example), a reciprocating tool feeding strategy is adopted, and the tool moves along toolpaths I to II. In this process, to ensure that the cutting thickness of the layer is the same, the tool position is changed from position I through position $i$, gradually transitioned to position II, and in different positions the tool is tangent to the cylindrical surface of the same radius, thereby completing the cutting process of this layer. As indicated above, three steps are required to realize the tooth groove cutting process. First, the first layer of cutting toolpaths I and II should be calculated according to the tooth surface grid points and cutting conditions. Second, the reciprocating toolpath is obtained according to the transformation of toolpaths I and II. Finally, the tool radially feeds to repeat the single layer cutting process to realize the complete tooth groove cutting process. 


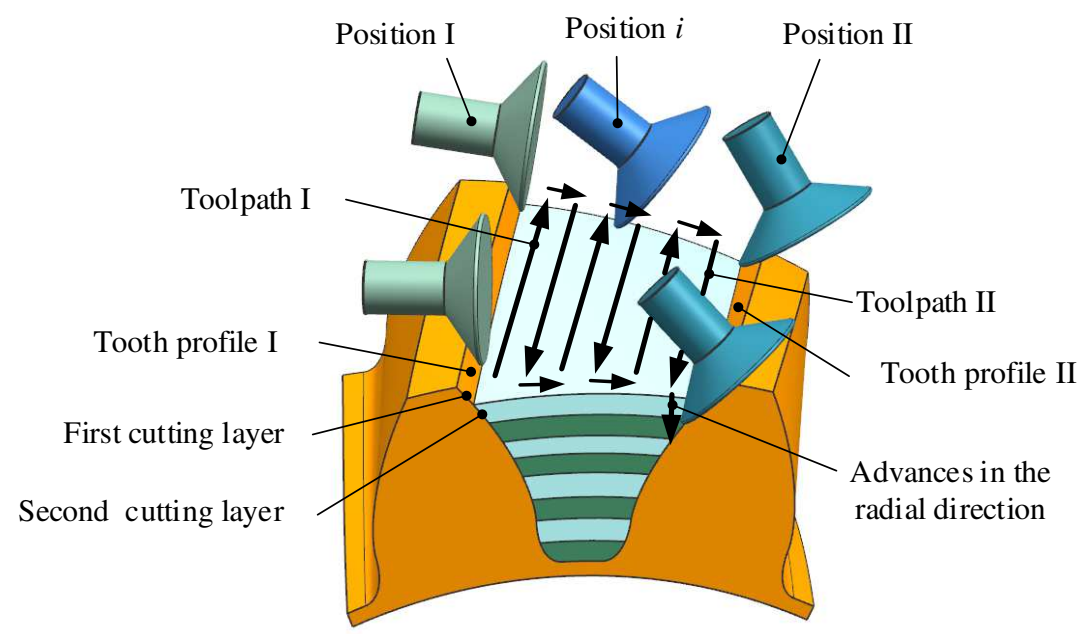

Fig. 3 Schematic diagram of milling path planning for disk milling cutter

\section{1 Tool location of tooth grooves cutting}

The principle of calculating the tool position point for machining helical gears with disc milling cutters is shown in Fig. 4. The Cartesian coordinate systems $S_{g}=\left\{O_{g}, x_{g}, y_{g}, z_{g}\right\}$ and $S_{t}=\left\{O_{t}, x_{t}, y_{t}, z_{t}\right\}$ are rigidly connected to the coordinates of the gear and cutting tool, respectively. According to the principle of generating, the cutting tool surface and tooth surface must meet the condition of overlap and tangency at the cutting point. For tooth profile I, the tangent vector $\tau_{P}$ coincides with the disc milling cutter side edge vector, and the normal vector $\boldsymbol{n}_{P}$ coincides with the reverse at the cutting point $P$ (conjugate point $P_{1}$ ) in the gear coordinate system. Profile II satisfies the same conditions at the point $P_{0}$ (conjugate point $P_{2}$ ). Considering tooth profile I as an example, the equation to satisfy the cutting conditions can be expressed as follows:

$$
\begin{aligned}
& \left\{\begin{array}{l}
\boldsymbol{\tau}_{P}=\boldsymbol{\tau}_{P_{1}} \cdot M_{O_{g} O_{t}} \\
\boldsymbol{n}_{P}=\boldsymbol{n}_{P_{1}} \cdot M_{O_{g} O_{t}}
\end{array}\right. \\
& \boldsymbol{r}_{P}=\boldsymbol{r}_{P_{1}}+\boldsymbol{r}_{O_{g} O_{t}}
\end{aligned}
$$

Where $\boldsymbol{r}_{O_{g} O_{t}}$ is the vector from $S_{g}$ to $S_{t}$, which can be expressed as follows:

$$
\boldsymbol{r}_{O_{g} O_{t}}=\left(\begin{array}{lll}
d_{x} & d_{y} & d_{z}
\end{array}\right)
$$

Where $\boldsymbol{\tau}_{P}$ and $\boldsymbol{n}_{P}$ are the tangent and normal vectors of the tooth surface point $P$, respectively, which can be expressed as:

$$
\begin{gathered}
\boldsymbol{\tau}_{P}=\left(\begin{array}{c}
r_{b} \cdot \mu \cdot \cos (\mu-\delta+\varphi) \\
r_{b} \cdot \mu \cdot \sin (\mu-\delta+\varphi) \\
0
\end{array}\right)^{T} \\
\boldsymbol{n}_{P}=\left(\begin{array}{c}
r_{b}^{2} \cdot \mu \cdot \sin (\mu-\delta+\varphi) \cdot \cot \left(\beta_{b}\right) \\
-r_{b}^{2} \cdot \mu \cdot \cos (\mu-\delta+\varphi) \cdot \cot \left(\beta_{b}\right) \\
r_{b}^{2} \cdot \mu
\end{array}\right)
\end{gathered}
$$

Here $\boldsymbol{\tau}_{P 1}$ and $\boldsymbol{n}_{P 1}$ are the tangent and normal vectors of the cutting point $P_{1}$ on the side edge of the 
disc milling cutter, respectively. When the disc milling tool is machined, the tool rotates around the spindle $+z_{t}$ at high speed, and the vector $\boldsymbol{\tau}_{P 1}$, normal vector $\boldsymbol{n}_{P 1}$, and position vector $\boldsymbol{r}_{P_{1}}$ at the cutting point $P_{1}$ (or $P_{2}$ ) should always satisfy the cutting conditions, which can be expressed as

$$
\begin{aligned}
& \boldsymbol{\tau}_{P_{1}}=\left(\begin{array}{lll}
0 & \cos \left(\alpha_{t}\right) & \sin \left(\alpha_{t}\right)
\end{array}\right) \\
& \boldsymbol{n}_{P_{1}}=\left(\begin{array}{c}
0 \\
\sin \left(\alpha_{t}\right) \cdot\left(l-l_{1} \cdot \cos \left(\alpha_{t}\right)+r \cdot \sin \left(\alpha_{t}\right)\right) \\
\cos \left(\alpha_{t}\right) \cdot\left(l-l_{1} \cdot \cos \left(\alpha_{t}\right)+r \cdot \sin \left(\alpha_{t}\right)\right)
\end{array}\right)^{T} \\
& \boldsymbol{r}_{P_{1}}=\left(\begin{array}{c}
0 \\
l-l_{1} \cdot \cos \left(\alpha_{t}\right)+r \cdot \sin \left(\alpha_{t}\right) \\
r+l_{1} \cdot \sin \left(\alpha_{t}\right)
\end{array}\right)^{T}
\end{aligned}
$$

Where $M_{O_{g} O_{t}}$ is the transfer-matrix from $S_{g}$ to $S_{t}$, which can be expressed as follows:

$$
M_{O_{g} O_{t}}=\left(\begin{array}{lll}
\boldsymbol{a} & \boldsymbol{b} & \boldsymbol{c}
\end{array}\right)
$$

Here, the column vector $\boldsymbol{a}, \boldsymbol{b}, \boldsymbol{c}$ is the vector expression of $+x_{t},+y_{t},+z_{t}$ in the gear coordinate system $S_{g}$, which can be expressed as follows:

$$
\boldsymbol{a}=\left(\begin{array}{lll}
a_{x} & a_{y} & a_{z}
\end{array}\right)^{T}, \quad \boldsymbol{b}=\left(\begin{array}{lll}
b_{x} & b_{y} & b_{z}
\end{array}\right)^{T}, \quad \boldsymbol{c}=\boldsymbol{a} \times \boldsymbol{b}
$$

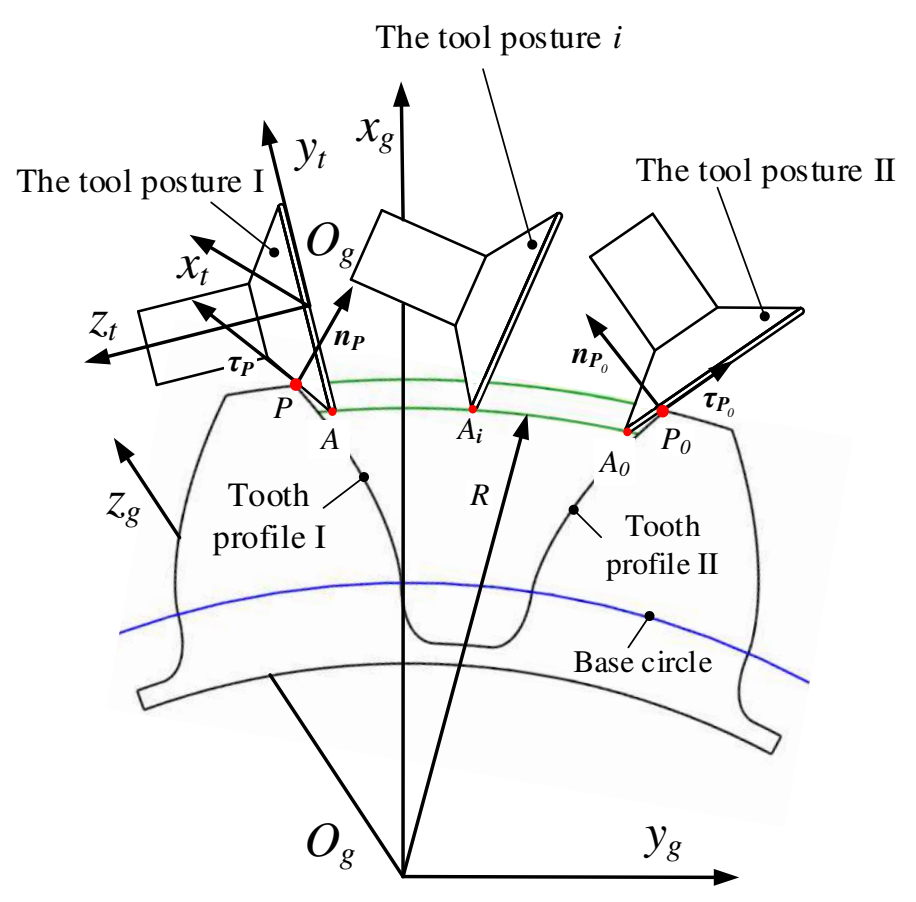

Fig. 4 Cutter position calculation for generating helical gear with disk milling cutter

The process calculation flow is shown in Fig. 5. Given the initial tooth surface parameters $\mu, \varphi$ and the tool cutting edge parameters $l_{1}, l_{2}$ at the cutting point $P$, calculate the tangent vector and the normal vector at this point according to Eqs.10-13. Subsequently, solve the system of equations according to Eq.7 to obtain the matrix $M_{O_{g} O_{t}}$, which is the transformation matrix in the coordinate system $S_{g}$. Finally, find the vector $r_{O_{g} O_{t}}$ according to Eq. 8, which is the tool location point vector in the coordinate system $S_{g}$. Similarly, the transformation matrix and the tool location point vector at the cutting point $P_{0}$ can be obtained. 


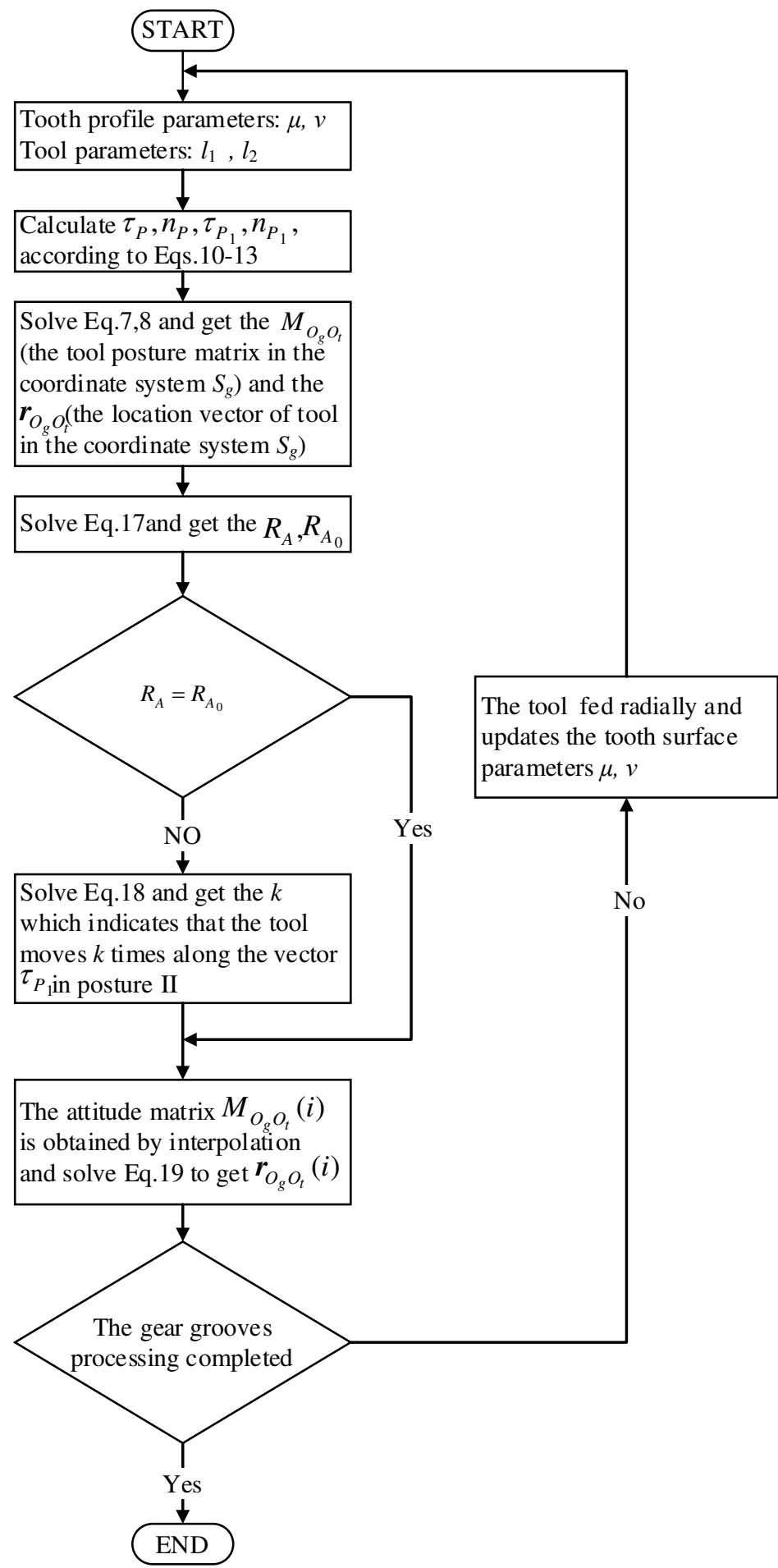

Fig. 5 Process calculation flow chart

As shown in Fig. 4, the depth of cut at the cutting point $P$ and $P_{0}$, is determined by the point $P_{3}$ on the fillet. The point $P_{3}$ satisfies the coincidence with point $A, A_{0}$ and the normal vector reversal. The point $A$ and $A_{0}$ are located on a cylindrical surface with a radius of $R$. The cylindrical surface can be expressed as follows:

$$
\boldsymbol{r}_{A, A_{0}}=\left(\begin{array}{lll}
R \cdot \cos \left(\theta_{R}\right) & R \cdot \sin \left(\theta_{R}\right) & Z
\end{array}\right)
$$

For posture I, the equation that satisfies the condition can be expressed as follows: 


$$
\left\{\begin{array}{c}
\boldsymbol{r}_{P_{3}}=\boldsymbol{r}_{A}+\boldsymbol{r}_{O_{g} O_{t}}(\mathrm{I}) \\
\boldsymbol{n}_{P_{3}}=\boldsymbol{n}_{A} \cdot M_{O_{g} O_{t}}(\mathrm{I})
\end{array}\right.
$$

In Eq. 17, $\boldsymbol{n}_{P_{3}}$ and $\boldsymbol{n}_{A}$ are calculated by Eq. 6 and 16, respectively, and the radius R of the cylindrical surface is obtained by solving the system of equations. For posture II, to ensure that the layer cutting thickness is the same, the points $A$ and $A_{0}$ should be located on the cylindrical surface of the same radius; therefore, the tool control point at position II should be moved $k$ times along the vector $\boldsymbol{\tau}_{P_{0}}$. The equation satisfying the condition can be expressed as follows:

$$
\left\{\begin{array}{c}
\boldsymbol{r}_{P_{3}}=\boldsymbol{r}_{A_{0}}+\left(\boldsymbol{r}_{O_{g} O_{t}}(\mathrm{II})+k \cdot \boldsymbol{\tau}_{P_{0}}\right) \\
\boldsymbol{n}_{P_{3}}=\boldsymbol{n}_{A_{0}} \cdot M_{O_{g} O_{t}}(\mathrm{III})
\end{array}\right.
$$

The tool control point vector after the move is obtained By solving the system of equations and finding the parameter $k$. The vector $\boldsymbol{r}_{A_{i}}$ of point $A_{i}$ is obtained by interpolating equidistantly between points $A$ and $A_{0}$ according to the disc milling cutter cutting width; the transformation matrix $M_{O_{g} O_{t}}(i)$ of posture $i$ is obtained by interpolating transformation matrices I and II. According to Eq. 19, the tool control point position vector $\boldsymbol{r}_{O_{g} O_{t}}(i)$ at position $i$ is obtained by solving the system of equations. Thus, an intermediate reciprocating tool path was obtained.

$$
\left\{\begin{array}{l}
\boldsymbol{r}_{P_{3}}=\boldsymbol{r}_{A_{i}}+\boldsymbol{r}_{O_{g} O_{t}}(i) \\
\boldsymbol{n}_{P_{3}}=\boldsymbol{n}_{A_{i}} \cdot M_{O_{g} O_{t}}(i)
\end{array}\right.
$$

When the first layer of cutting is completed, the tool feeds along the radial direction, and an equal residual height tool path planning strategy is adopted, as shown in Fig. 6.

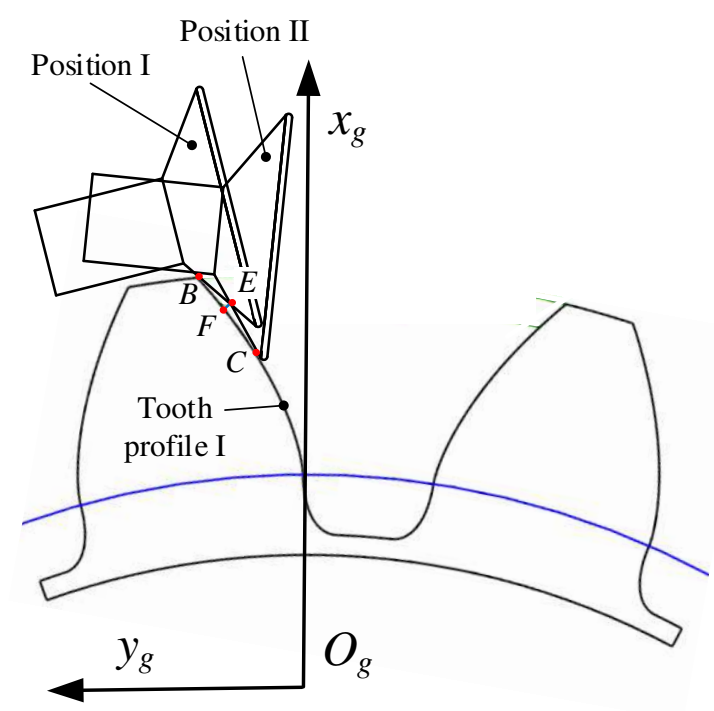

Fig. 6 Equal residual height generating of disc milling cutter

When the disc milling cutter is in position I (corresponding to the first layer of toolpath I), the cutting point with tooth profile I is B. When the disc milling cutter is in position II (corresponding to the second layer of toolpath I), the cutting point with tooth profile I is C. The cutting edge of the disc milling cutter intersects at point $\mathrm{E}$ in the two adjacent positions, and a straight line is made through point $\mathrm{E}$ perpendicular to tooth profile 
I, with the vertical foot F. The length of the straight line EF is the residual height of the tooth surface. The calculation method adopted in [7] and [8] can obtain the tooth surface parameters of the adjacent cutting point $\mathrm{C}$ according to the tooth surface parameters of the initial cutting point $\mathrm{B}$. According to the cutting point $\mathrm{C}$, the second-level cutting toolpaths I and II and reciprocating toolpaths are obtained, and it is cycled to obtain all the cutting toolpaths of the tooth groove.

\section{2 Interference checking clearance side of cutter}

According to the generation principle of the tooth milling cutter path of the disk milling cutter, the interference in the machining process mainly comes from the interference cutting between the bottom plane of the milling cutter and tooth profile II when the side edge of the disk milling cutter is processing tooth profile I, as shown in Fig. 7.

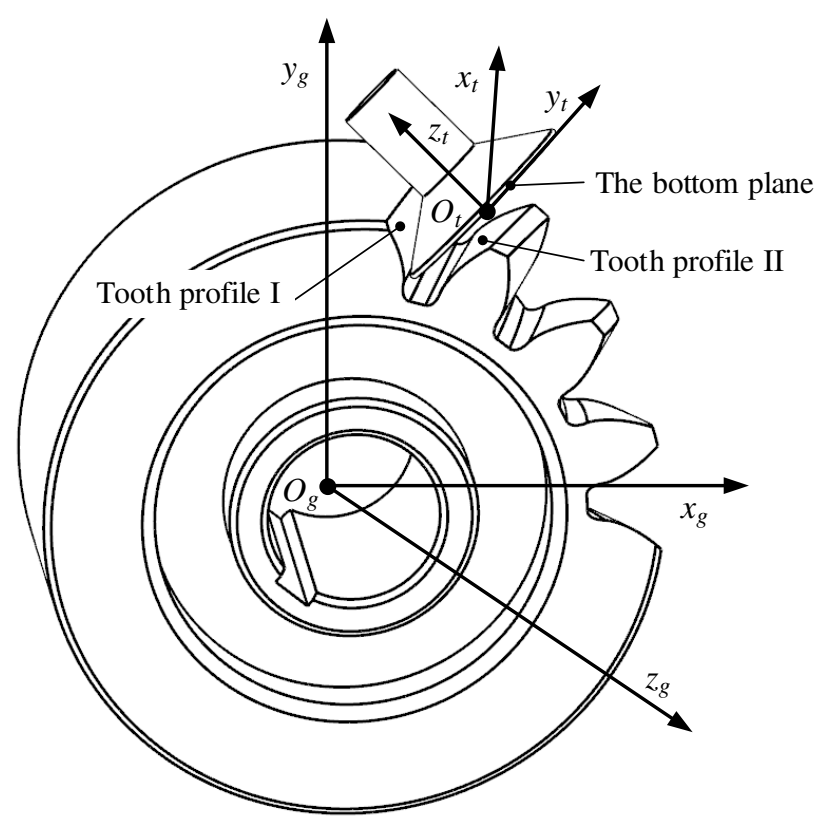

Fig. 7 Interference cutting in generating process of disk milling cutter

From the point-to-surface distance theory, it is known that when the normal vector on the tooth surface intersects with the tool bottom, the distance between the two points is the shortest distance from that point to the tooth surface, and the calculation formula can be expressed as follows:

$$
\begin{gathered}
\boldsymbol{r}_{D}=\left(r_{d} \cdot \cos \left(\theta_{d}\right) \quad r_{d} \cdot \sin \left(\theta_{d}\right) \quad 0\right) \cdot M_{O_{g} O_{t}}(i) \\
\boldsymbol{r}_{d}-\boldsymbol{r}_{P_{0}}=N \cdot \boldsymbol{n}_{P_{0}} \\
d=\left|\boldsymbol{r}_{d}-\boldsymbol{r}_{P_{0}}\right|
\end{gathered}
$$

In Eq. 20, $\boldsymbol{r}_{D}$ is the position vector of the bottom plane of the disc milling cutter in the gear coordinate system when the tool is in posture $i ; r_{d}$ is the radius of the bottom surface with a value range is $0-l$; and $N$ is a constant. The point on the tooth surface corresponding to the shortest distance can be determined using Eq.21, and the shortest distance $d$ from the bottom surface to tooth profile II is determined using Eq. 22. If $d$ is less than 0 , interference will occur; otherwise, it does not. When interference occurs, the bottom surface can 
be moved away from tooth profile II by reducing the tool angle $\alpha_{t}$.

\section{Comparative analysis of cutting efficiency}

To verify that the disc milling cutter has a higher machining efficiency, the end milling cutter is used as the experimental comparison object. In the process of tooth milling, tool deformation is an important factor that affects the quality of tooth surface machining. Therefore, to ensure the quality of tooth surface machining, the strength and cutting efficiency per unit time of the disc milling cutter and end milling cutter were compared under the same deformation and linear cutting speed conditions. According to the tool material (both disc milling cutter insert and end milling cutter are carbide steel), the cutting line speed is $94 \mathrm{~m} / \mathrm{min}$. According to the basic gear parameters, the maximum diameter that can be used for rough milling gears with end milling cutter is $6 \mathrm{~mm}$ and the number of cutting blades is 2. Using a finite element analysis software, the cutting force load is added to the cutting edge of the tool model, and the deformation results of the load applied to the disc milling cutter and end milling cutter were obtained through analytical calculations, as shown in Fig. 8.

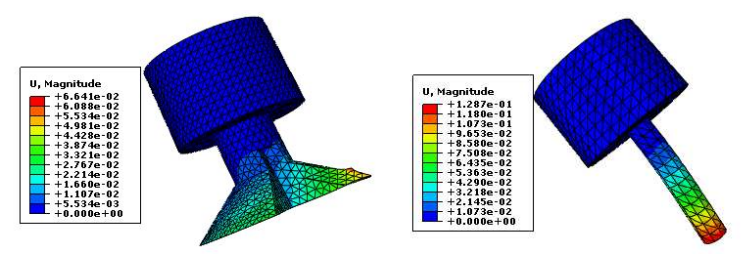

Fig. 8 Results of finite element analysis of tool load-deformation

The deformation data were extracted and processed to obtain the relationship between the load and deformation of the two tools, as shown in Fig. 9.

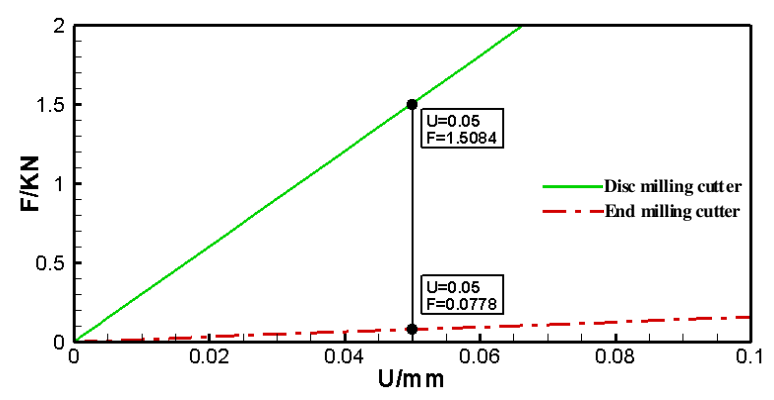

Fig. 9 Tool load-deformation diagram

Fig. 9 shows that under the same deformation conditions, the disc milling cutter bears a load of $1508 \mathrm{~N}$ and the end milling cutter has a bearing capacity of $77.8 \mathrm{~N}$. The former is approximately 20 times greater than the latter, indicating that the strength of the disc milling cutter is much greater than that of the end milling cutter, and the disc cutter can bear a larger cutting amount.

The simplified cutting model was simulated using the special metal cutting simulation software AdvantEdge. In Fig. 10(a), (b), and(c) represent the cutting simulation experiment of the disk milling cutter, and Fig. 10 (d), (e), and(f) represent the cutting simulation experiment of the end milling cutter. Fig. 10(a) and (d) show the relative motion relationship between the tool and workpiece in the simplified cutting model. Fig.10 (b) and (e) show the simulation results obtained using AdvantEdge. Fig. 10 (c) and (f) show the changes in 
cutting forces $F x, F y$, and $F z$ in the process of cutting simulation.
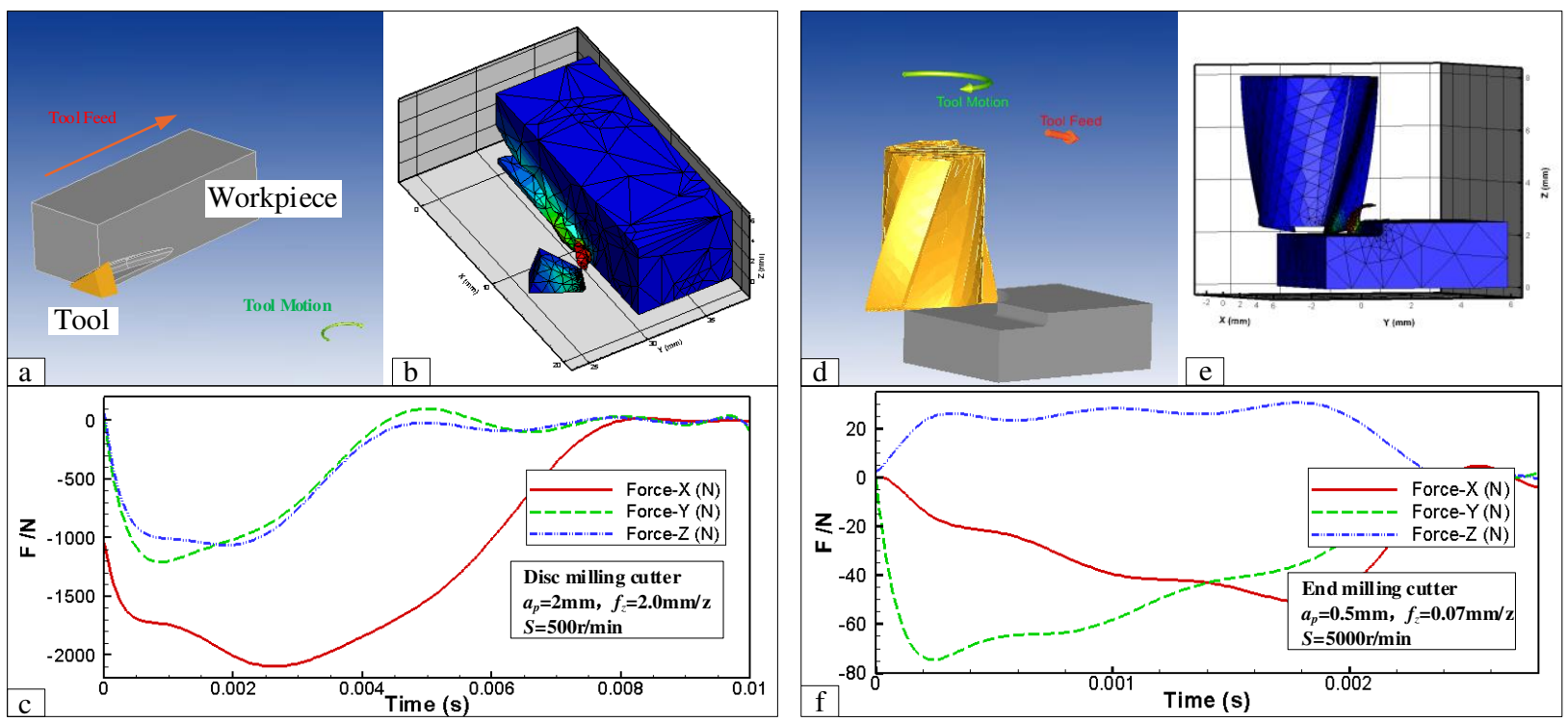

Fig. 10 AdvantEdge simulation results of cutting force. a Relative motion relationship between the disc milling cutter and workpiece. b Simulation results of the disk milling cutter. $\mathbf{c}$ Simulation of cutting force of the disk milling cutter. $\mathbf{d}$ Relative motion relationship between the end milling cutter and workpiece. $\mathbf{e}$

Simulation results of the disk milling cutter. $\mathbf{f}$ Simulation of cutting force of the end milling cutter.

By synthesizing the cutting force, the cutting force $F$ under different cutting parameters is obtained, and the results of the finishing experiment are listed in Table 1.

Table 1 Efficiency comparison table

\begin{tabular}{ccccc}
\hline & $f_{z} / \mathrm{mmg}^{-1}$ & $\mathrm{~F} / \mathrm{N}$ & $U / \mu m$ & $V F S / \mathrm{mm}^{3} \mathrm{gs}^{-1}$ \\
\hline & 0.4 & 424.67 & 14.1 & 17.15 \\
Disc milling cutter & 1.0 & 1217.73 & 40.4 & 42.72 \\
$a_{p}=2 \mathrm{~mm}$ & 1.5 & 1606.85 & 53.3 & 63.54 \\
$S P=500 \mathrm{rgmin}^{-1}$ & 2.0 & 1888.24 & 62.7 & 84.44 \\
\hline & 0.05 & 56.18 & 36.1 & 16.66 \\
End milling cutter & 0.06 & 57.33 & 36.8 & 19.99 \\
$a_{p}=0.5 \mathrm{~mm}^{-1}$ & 0.07 & 65.33 & 42.1 & 23.32 \\
$S P=5000 \mathrm{rgnin}^{-1}$ & 0.08 & 85.09 & 54.7 & 26.65 \\
\hline
\end{tabular}

$\mathrm{U}$ : The deformation of tool

VFS: The volume of material removed per unit time

The deformation of the tool in Table 1 was obtained by interpolating the load-deformation diagram. The volume of material removed per unit time in Table 1 was obtained by multiplying the removal volume per tooth of the tool by the rotational speed per second. The removal volume per tooth was obtained by Boolean operation using the tool model and the blank model, as shown in Fig. 11. After the Boolean difference operation between the $(i-1)$ th blade and the workpiece is completed, the blade moves $f_{z}$ along the feed direction to the $i$ th blade position and performs the same Boolean operation. The cutting volume per tooth can be obtained by comparing the volume of the workpiece obtained twice. Table 1 indicates that the deformation of the disc and end milling 
cutters increases with the increase in feed per tooth and cutting volume under the condition of constant back feed $\left(a_{p}\right)$.
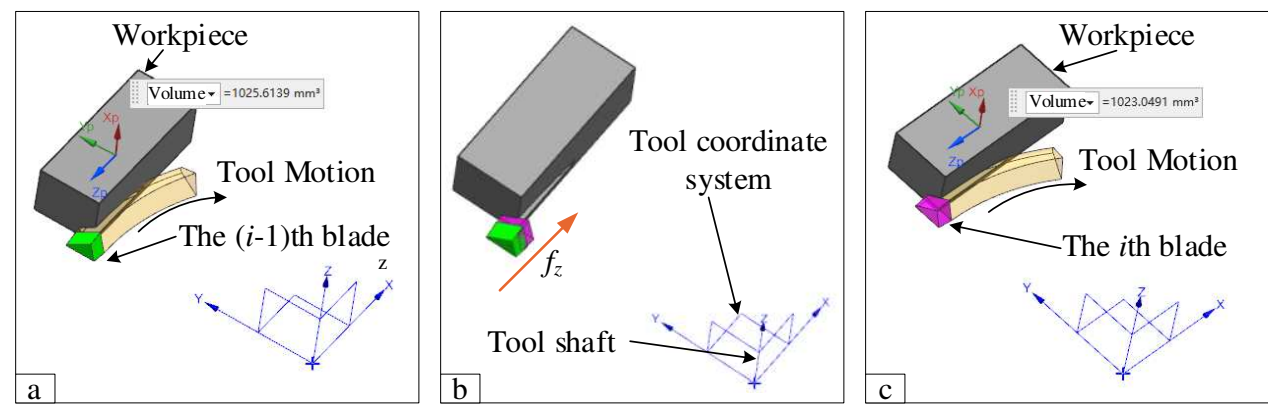

Fig. 11 Removal volume of each tooth obtained by Boolean operation. a Relative position between (i-1)th blade and workpiece. $\mathbf{b}$ Blade moves $f_{z}$ along the feed direction. $\mathbf{c}$ Relative position between $i$ th blade and workpiece

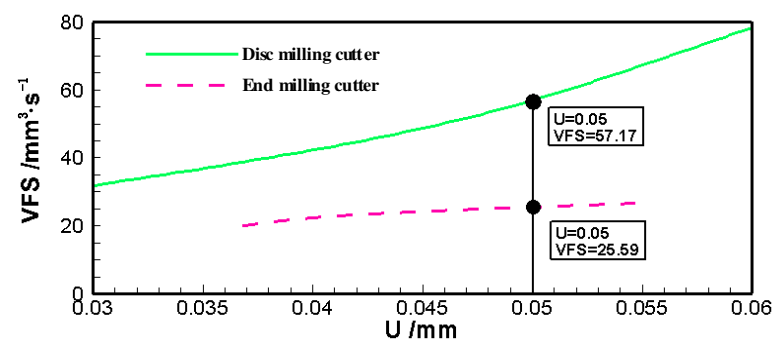

Fig. 12 Relationship between tool removal volume per unit time and tool deformation

As shown in Fig. 12, through the interpolation calculation, we find that in the deformation amount $U=0.05$ $\mathrm{mm}$, the removal volume per unit time is $57.17 \mathrm{~mm}^{3}$ for disc milling cutter and $25.59 \mathrm{~mm}^{3}$ for end milling cutter, and the former is 2.2 times of the latter. With an increase in the deformation amount, the ratio of removal volume per unit time of both tends to increase. However, to ensure the quality of tooth surface machining, the deformation amount of the tool should be within a reasonable range. According to Table 1 and the removal volume per unit time, the approximate cutting parameters $a_{p}$ and $f_{z}$ are determined. The tool path planning strategy described in Section 3 is adopted to plan the tool path of the disk milling cutter and end milling cutter, and the tool path is imported into 3D modeling software, as shown in Fig. 13. The left and right figures show the motion path of the control point of the end milling cutter and the disc milling cutter in Fig. 13, respectively. Through the given feed rate $f_{z}$ and post-processing, the simulation processing time of the disk milling cutter and the end milling cutter in 3D modeling software can be obtained, as shown in Fig. 13. The results of the simulation processing time demonstrate that, compared with the end milling cutter, the time of machining a tooth groove with the disc milling cutter is reduced by $2.91 \mathrm{~min}$, and the efficiency is increased by $54 \%$. 


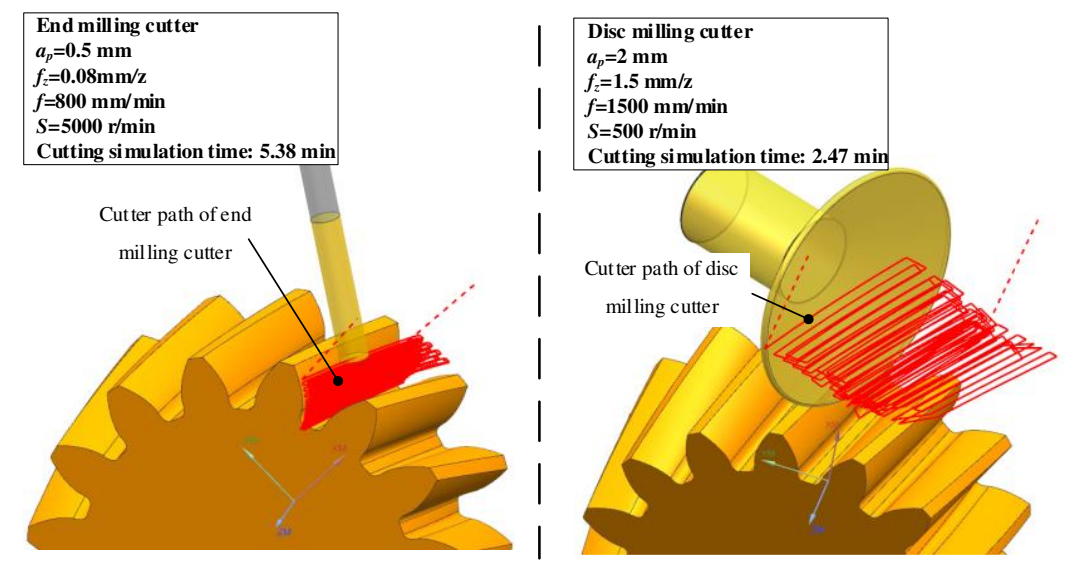

Fig. 13 Comparison of cutting simulation time

\section{Machining experiment}

To verify the solution equation for the location of the tool position using the disc cutter, a cylindrical gear milling process experiment (gear parameters and disc milling tool parameters are shown in Table 2) was conducted. The experiment included a cutting simulation experiment and actual machining experiment.

Table 2 Gear parameters and disc milling cutter parameters

\begin{tabular}{ccc}
\hline Items & symbol & value \\
\hline Tooth number & $z_{1}$ & 15 \\
Module & $m_{n} / m m$ & 5 \\
Helix angle & $\left.\beta / /^{\circ}\right)$ & 15 \\
Pressure angle & $\alpha_{n} /\left(^{\circ}\right)$ & 20 \\
Modification coefficient & $x_{1}$ & 0.23 \\
Face width & $b / m m$ & 40 \\
Addendum coefficient & $h_{a}^{*}$ & 1 \\
Bottom clearance coefficient & $c^{*}$ & 0.25 \\
\hline & $r_{I D} / \mathrm{mm}$ & 30 \\
Disc milling tool & $\alpha_{t} /\left(^{\circ}\right)$ & 35 \\
& Number of blades & 2 \\
\hline
\end{tabular}

A 5-axis simultaneous gear milling simulation platform (AC linkage) was established based on the machine structure of the KMC600SU machining center, as shown in Fig. 14(a). The tool location of tooth groove cutting is calculated as described in Section 3, and then rewrites it to NC programs. Subsequently, the $\mathrm{NC}$ program was imported into the milling simulation platform to obtain the cutting results. The process of cutting simulation is shown in Figs. 14(b) and (c), and the movement of each axis of the machine tool in the process of cutting simulation is shown in Fig. 15. The error between the gear model obtained from the machining simulation and the theoretical model was obtained, and the results are shown in Fig. 14(d). 

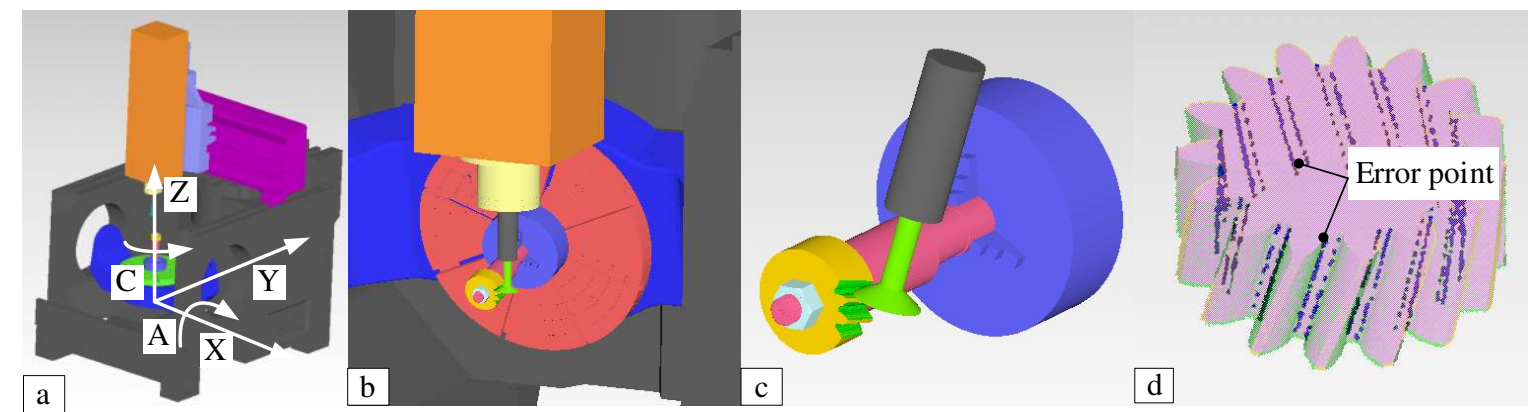

Fig. 14 Cutting simulation experiment and error comparison results. a 5-axis simultaneous gear milling simulation platform. b Simulation process of gear cutting. c Simulation process of gear cutting. d Error between the gear model obtained from the machining simulation and the theoretical model.

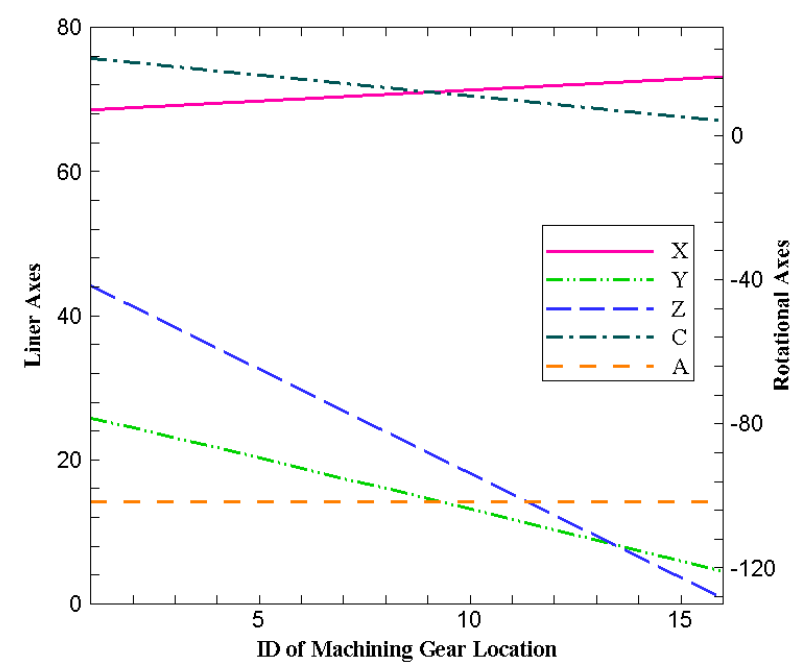

Fig. 15 Movement of each axis of machine tool in the process of cutting simulation

Fig. 14(d) shows that there is no error point on the tooth surface, implying that the simulated cutting surface and the theoretical tooth surface completely coincide, and all the blue error points are distributed at the root, which may be because of the straight-line transition in the simulation machining of the root, while the theoretical root transition is fillet. In the actual cutting experiment, the KMC600SU 5-axis machining center was used for tooth cutting, as shown in Fig. 16(a). The machine motion and machining results during the machining process are the same as the machine motion and results during the simulation, as shown in Fig. 16(b).
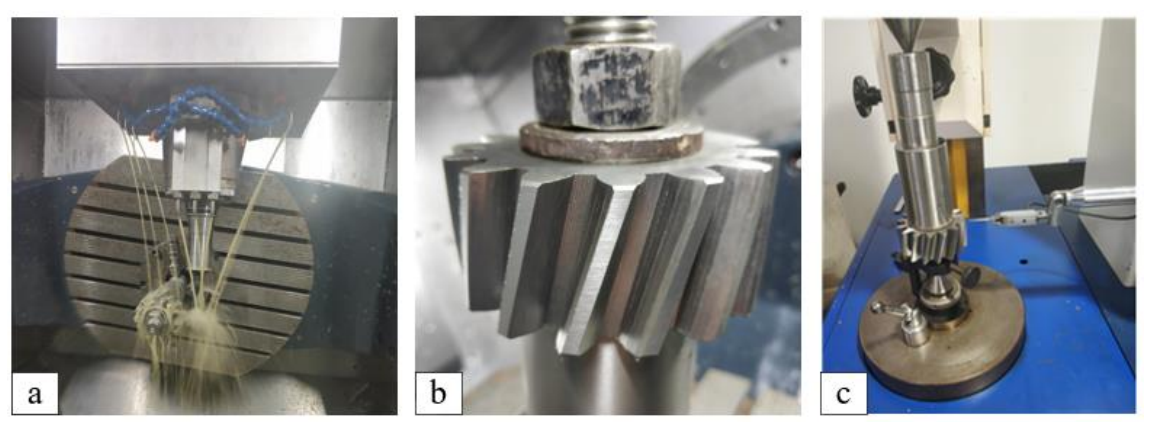

Fig. 16 Experiment of gear milling with disc milling cutter. a KMC600SU 5-axis machining center. b Experimental results of gear cutting. c Measuring gear profile deviation and helix deviation. 
The gear profile deviation and helix deviation were measured by a gear measuring center, as shown in Figure 16(c). The maximum value of profile form deviation is $8.3 \mu \mathrm{m}$, and the accuracy grade is ISO-0006; the maximum value of profile slope deviation is $-14.4 \mu \mathrm{m}$, and the accuracy grade is 8, as shown in Fig. 17 . The maximum value of helix form deviation is $9.5 \mu \mathrm{m}$ and the accuracy grade is 7 ; the maximum value of helix slope deviation is $-10.3 \mu \mathrm{m}$, and the accuracy grade is 7 , as shown in Fig. 18. Considering there is finishing process after this process, this machined gear meets the rough machining accuracy requirements. The deviation comes from the following aspects: (1) the overhang of the fixture is too long due to the structural limitation of the machine tool; (2) during the roughing process, the larger cutting parameters $a_{p}$ and $f_{z}$ are adopted; (3) there is an eccentric deviation between the workpiece axis and the machine $\mathrm{C}$-axis axis. Further, both profile slope and helix slope deviations are higher than profile form and helix form deviations, indicating that the mounting deviation had a greater influence on the machining. If the mounting conditions are improved and the machining process parameters are changed, the deviations in rough machining of gears can be effectively reduced, and the machining method can be applied to the gear finishing process.

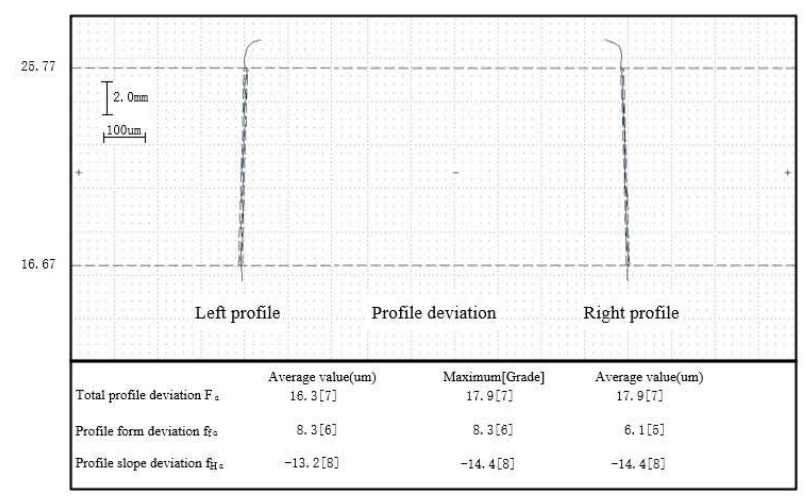

Fig. 17 Measurement results of Profile deviation

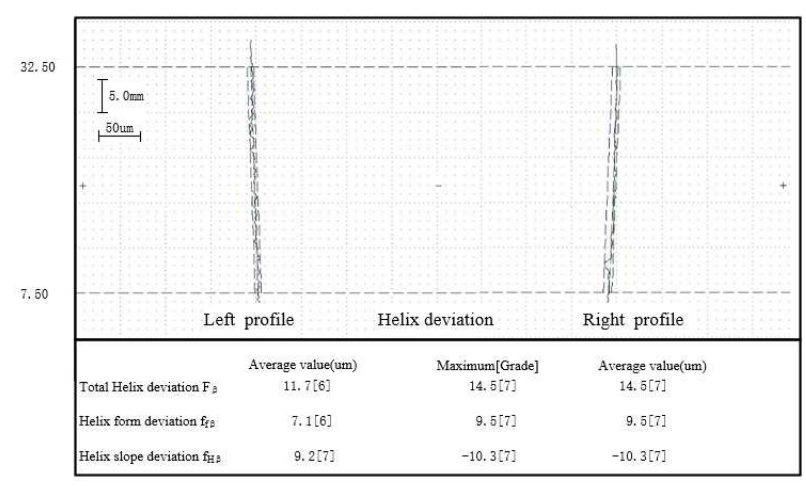

Fig. 18 Measurement results of Helix deviation

\section{Conclusions}

Aiming at the development trend of gear processing to small-scale customization, a gear processing method using large-diameter indexable disc milling cutters instead of end milling cutters for digital generating milling of tooth is proposed in this study to solve the problem of low efficiency of end milling cutters for processing small and medium-sized gears. By establishing a unified mathematical model of the helical gear and disc milling cutter, the relative position of the tool and tooth face and the relative transformation matrix 
relationship during the gear milling process are derived, and a general scheme of tool path planning is provided. Thereafter, the tool position location solution equation is also described, and the efficient digital generating machining of helical gears with disk milling cutters is realized. The results obtained in this study were as follows:

(1)The results of the finite element analysis show that the milling efficiency of disc milling cutters is significantly higher than that of end milling cutters under the same cutting line speed and tool deformation conditions. The material removal per unit time of the disc milling cutter is 2-3 times that of the end milling cutter, and the cutting time of the former is reduced by $54 \%$ compared with the latter.

(2) The high strength of the disc milling cutter facilitates faster removal of the workpiece material in rough machining and increases the machining efficiency. The digital generating method of the disc milling cutter helps to reduce the number of tool movements and improves the machining efficiency, which is ideal for singlepiece and small batch gear machining.

\section{Funding}

We would like to thank the financial aid and support from the National Key Research and Development Program of China (No. 2020YFB2010202), the National Science Foundation of China (No.51775073, No. 51805060), Science and Technology Research Program of Chongqing Municipal Education Commission under Grant (No.KJQN201901107).

\section{Conflicts of interests}

The authors do not think there is any conflict of interest.

\section{Availability of data and material}

The data that support the findings of this study are available from the corresponding author upon reasonable request.

\section{Code availability}

Not applicable.

\section{Ethics approval}

This is an original scientific paper. I would like to declare on behalf of my co-authors that the work described is original research that has not been published previously, and not under consideration for publication elsewhere, in whole or in part.

\section{Consent to participate}

Not applicable.

\section{Consent for publication}

All the authors listed have approved the manuscript that is enclosed and manuscript is approved by all authors for publication. 


\section{Authors' contributions}

Weiqing Zhang contributed to the conception of the study;

Qing Zhou performed the experiment and wrote the manuscript;

Xiaodong Guo contributed key technical guidance and manuscript revisions;

Rulong Tan helped perform the analysis with constructive discussions;

Ruizhi Shu assisted machining and measurement experiments.

\section{References}

[1] Bouzakis, K. D., Lili, E., Michailidis, N., \& Friderikos, O. (2008). Manufacturing of cylindrical gears by generating cutting processes: A critical synthesis of analysis methods. CIRP Annals, 57(2), 676-696. doi:10.1016/j.cirp.2008.09.001

[2] Dimitriou, V., \& Antoniadis, A. (2008). CAD-based simulation of the hobbing process for the manufacturing of spur and helical gears. The International Journal of Advanced Manufacturing Technology, 41(3-4), 347-357. doi:10.1007/s00170-008-1465-x

[3] Chen, Y., Cao, H. , Li, X. ,\& Chen, P.(2016). The Model of Spatial Forming with Multi-cutting-edge for Cylindrical Gear Hobbing and Its Application. Journal of Mechanical Engineering,52(09):176-183. (In Chinese)

陈永鹏, 曹华军, 李先广, \& 陈鹏. (2016). 圆柱齿轮滚切多刃断续切削空间成形模型及应用. 机械工程学报, 052(009), 176-183.

[4] Zhu, L., \&Lu, Y. (2013.)Modeling Swept Envelopes of Rotary Cutting Tools with Application to Five-axis Flank Milling. Journal of Mechanical Engineering, 49(07):176-183. (In Chinese)

朱利民, \& 卢耀安. (2013). 回转刀具侧铣加工扫掠包络面几何造型及其应用. 机械工程学报,049(007), 176-183.

[5] Bo, P., Bartoň, M., Plakhotnik, D., \& Pottmann, H. (2016). Towards efficient 5-axis flank CNC machining of free-form surfaces via fitting envelopes of surfaces of revolution. Computer-Aided Design, 79, 1-11. doi:10.1016/j.cad.2016.04.004

[6] Harik, R. F., Gong, H., \& Bernard, A. (2013). 5-axis flank milling: A state-of-the-art review. Computer-Aided Design, 45(3), 796-808. doi:10.1016/j.cad.2012.08.004

[7] Guo, E., Ren, N., Ren, X., \& Liu, C. (2019). An efficient tapered tool having multiple blades for manufacturing cylindrical gears with power skiving. The International Journal of Advanced Manufacturing Technology, 102(9-12), 2823-2832. doi:10.1007/s00170-018-03239-Z

[8] Tsai, C.-Y., \& Lin, P. D. (2017). Gear manufacturing using power-skiving method on six-axis CNC turn-mill machining center. The International Journal of Advanced Manufacturing Technology, 95(1-4), 609-623. doi:10.1007/s00170-017-1154-8

[9] Tang, J., \& Yang, X. (2015). Research on manufacturing method of planing for spur face-gear with 4-axis CNC planer. The International Journal of Advanced Manufacturing Technology, 82(5-8), 847-858. doi:10.1007/s00170-015-7417-3

[10] Lo, C. C. . (1999). Efficient cutter-path planning for five-axis surface machining with a flat-end cutter. Computer-Aided Design, 31(9), 557-566.

[11] Pechard, P.-Y., Tournier, C., Lartigue, C., \& Lugarini, J.-P. (2009). Geometrical deviations versus smoothness in 5-axis highspeed flank milling. International Journal of Machine Tools and Manufacture, 49(6), 454-461. doi:10.1016/j.ijmachtools.2009.01.005

[12] Shih, Y.-P., \& Chen, S.-D. (2012). Free-Form Flank Correction in Helical Gear Grinding Using a Five-Axis Computer Numerical Control Gear Profile Grinding Machine. Journal of Manufacturing Science and Engineering, 134(4). doi:10.1115/1.4006096

[13] Gong, H., \& Wang, N. (2011). 5-axis flank milling free-form surfaces considering constraints. Computer-Aided Design, 43(6), 563-572.

[14] Guo, E., Ren, N., Liu, Z., Zheng, X., \& Zhou, C. (2019). Study on tooth profile error of cylindrical gears manufactured by flexible free-form milling. The International Journal of Advanced Manufacturing Technology, 103(9), 4443-4451. 
[15] Michalski, J. (2008). Surface topography of the cylindrical gear tooth flanks after machining. The International Journal of Advanced Manufacturing Technology, 43(5-6), 513-528. doi:10.1007/s00170-008-1737-5

[16] Özel, C. (2012). A study on cutting errors in the tooth profiles of the spur gears manufactured in CNC milling machine. The International Journal of Advanced Manufacturing Technology, 59(1-4), 243-251.

[17] Svahn, M., Vedmar, L., \& Andersson, C. (2014, September). Gear tooth surface roughness of helical gears manufactured by a form milling cutter. In International gear conference (Vol. 1, pp. 96-106).

[18] Chiang, C.-J., \& Fong, Z.-H. (2010). Design of form milling cutters with multiple inserts for screw rotors. Mechanism and Machine Theory, 45(11), 1613-1627. doi:10.1016/j.mechmachtheory.2010.06.012.

[19] Zheng, F., Han, X., Lin, H., \& Zhao, W. (2021). Research on the cutting dynamics for face-milling of spiral bevel gears. Mechanical Systems and Signal Processing, 153. doi:10.1016/j.ymssp.2020.107488.

[20] Habibi, M., \& Chen, Z. C. (2016). A semi-analytical approach to un-deformed chip boundary theory and cutting force prediction in face-hobbing of bevel gears. Computer-Aided Design, 73, 53-65. doi:10.1016/j.cad.2015.12.001

[21] Shih, Y.-P., Sun, Z.-H., \& Wu, F.-C. (2017). A disk tool cutting method for bevel gear manufacture on a five-axis machine. The International Journal of Advanced Manufacturing Technology, 94(1-4), 855-865. doi:10.1007/s00170-017-0918-5

[22] Litvin, F. L., and Fuentes,A., 2004, Gear Geometry and Applied Theory, 2nded., Cambridge University Press. New York, Chaps. 16. 